\title{
Porosity and compatibility of repair mortars and Hungarian porous limestones
}

\author{
Balázs Szemerey-Kiss, Ákos Török \\ Department of Construction Materials and Engineering Geology, \\ Budapest University of Technology and Economics, Budapest
}

\begin{abstract}
Porosity and water absorption of different binder/aggregate ratios of repair mortar and porous limestone were studied that were used in many Hungarian monuments. Different types of mortars were analyzed by using mercury intrusion porosimetry (MIP) and the water saturation method (WSM). Test results showed that there was a strong correlation between the absorption mechanism and the porosimetric characteristics. Mechanical properties of the tested mortars were observed earlier. Pore size distribution confirms that the total porosity increases with increasing aggregate content. Natural stones mainly have medium and large pore radii $(1-100 \mu \mathrm{m})$ while repair mortars, even with increased aggregate ratio, have smaller pore radii $(0.01-0.1 \mu \mathrm{m})$. The comparison of different data allows us to state that pore characteristics such as pore volume, pore geometry, pore size distribution and network connectivity are the key control factors of stone and mortar deterioration.
\end{abstract}

Key words: compatibility, repair mortar, limestone, porosity, water absorption

\section{Introduction}

Deeply weathered stones of heritage buildings require being improved by repair mortars or replaced by new ones. In all cases when loss compensations are applied the main goal is to reach the best compatibility between the natural stone and the repair mortar. Beside the chemical, mechanical and physical compatibility, structural compatibility is also an important requirement. Moreover the repair mortar should work without causing damage, directly or indirectly. An

Addresses: B. Szemerey-Kiss, Á. Török: H-1111 Budapest, Múegyetem rkp. 3, Hungary, e-mails: szemerey@gmail.com, torokakos@mail.bme.hu

Received: December 21, 2011, accepted: March 26, 2012 
old recipe or an exact copy does not provide a guarantee for compatibility (Klisinska-Kopacz et al. 2010). In addition to compatibility, workability is also a very important aspect (low speed of setting, hardening without shrinkage and cracks, etc.).

Compatibility is certainly one of the most frequently used words in conservation practice. Nobody questions the importance of compatibility, but it can only be applied with great difficulty in real situations, because it is a complex concept. Several papers provide information about compatibility and risks of incompatibility when repair mortars for traditional masonry and ornamental stone work are used (Rodrigues and Grossi 2007, Prikryl and Štastná 2010, Prikryl et al. 2010). Strong variations of physical and mechanical properties of mortars are observed (Marques et al. 2006; Szemerey and Török 2011). Previous studies have been carried out in many ways, such as testing the compatibility of limestone and repair mortar (Papayianni 2006; Beck and Al-Mukhtar 2008; Szemerey and Török 2010; Szemerey and Török 2011). The mechanical properties depend on binder/aggregate type and ratio (Barsottelli et al. 2001; Sinan 2003; Lanas and Alvarez 2003; Pecchioni et al. 2005; Lanas et al. 2006; Pavia 2006; Siegesmund et al. 2007; Pavia et al. 2008), and of course on the mineralogical and chemical composition (Middendorf et al. 2005a; Middendorf et al. 2005b). Capillary movement of water in repair mortar is very important in loss compensation of stones. A greater difference between the stone and the repair mortar is due to the decay process in stone (freeze-thaw effects, crystallization of soluble salts, chemical and biological attack, etc.). Furthermore water transfer properties were also tested in several case studies (Binda et al. 2003; Maravelaki-Kalaitzaki et al. 2005; Karaca 2010). The connection of pore structure and mechanical properties of mortars were also observed earlier (Lanas and Alvarez 2003; Lanas et al. 2005). Mineralogical composition, structures and porosity were investigated and found to have been the principal responsible factors of the decay of the natural stones and mortars (Barsoletti et al. 2000). Previous studies reported the mercury intrusion method (MIP) with other options, such as the water vapor adsorption method (WVM) and water saturation method (WSM), suitable for the analysis of the full spectrum of pore sizes ranging from very fine to very coarse. The combinations of these methods are most commonly used in practice for studies on stones (Laskar et al. 1997; Kate and Gokhale 2006). The aim of this experimental study was to investigate the porosimetric characteristics and the pore structure of mortars and natural stones in order to assess these properties as control factors of compatibility between porous limestone and repair mortars. These results can be used in the development of new repair mortars and in the selection of proper mortars for the restoration of porous limestone monuments. 


\section{Materials and methods}

\section{Sample preparation}

Repair mortars (Fig. 1) were compared to the typical Hungarian porous limestone from Sóskút Quarry (Fig. 2), the most common natural stone used in monuments. This porous, oolitic limestone has a low density, a high total porosity and is easy to work with. The grain size of the stone is variable, from very finegrained through middle to coarse-grained. In the experiments four types of commercially available repair mortars that are widely employed for loss compensation of porous oolitic limestones were used. An additional type that was prepared in our laboratory was also tested. Twelve different sample sets (Table 1), three mixtures per series were prepared: i) pure repair mortar, ii) $70 \mathrm{wt} \%$ repair mortar +30 wt. $\%$ limestone sand as aggregate and iii) 50 wt.\% repair mortar + 50 wt. $\%$ of limestone sand aggregate. The repair mortars were deposited under laboratory conditions for 90 days after casting. During the preparation of samples and during the experiments, extreme conditions (warm/cold environment) were avoided. The limestone sand (max. $2 \mathrm{~mm}$ in diameter), which is a ground oolitic limestone, was obtained from Sóskút Quarry.

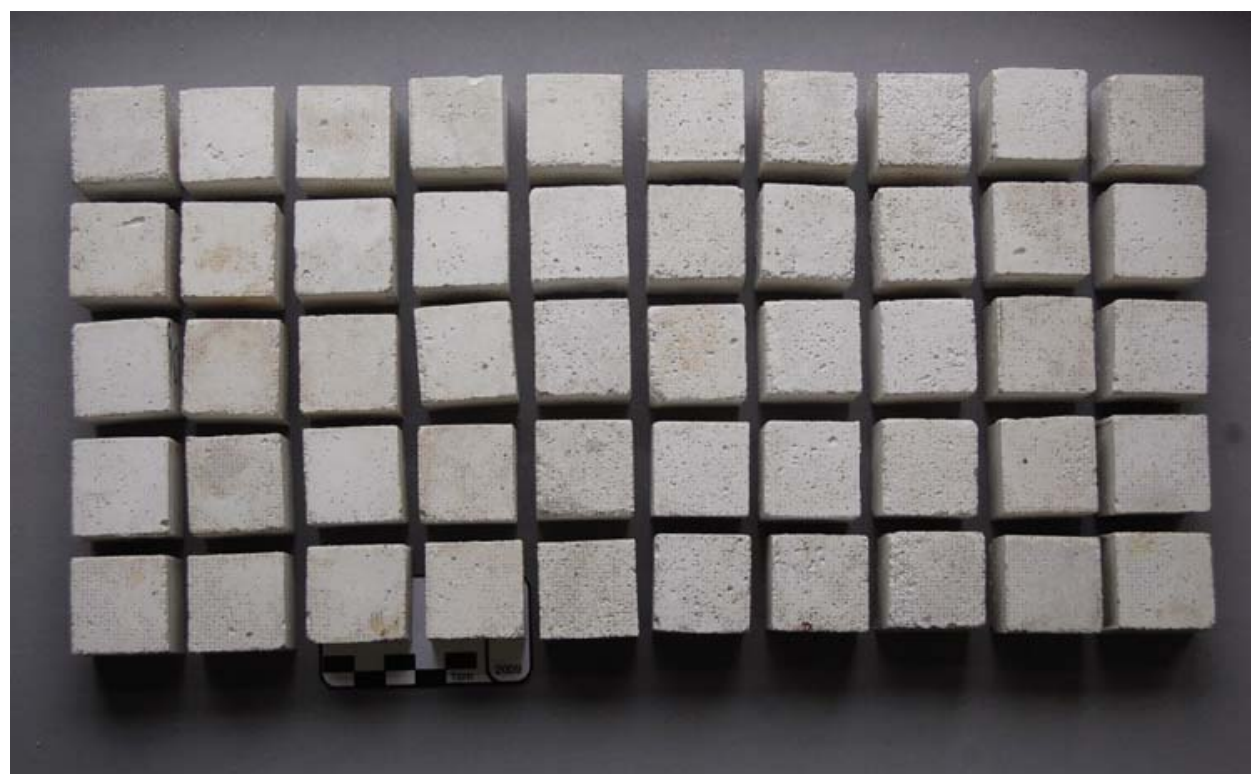

Fig. 1

Repair mortar specimens after being removed from the molds 


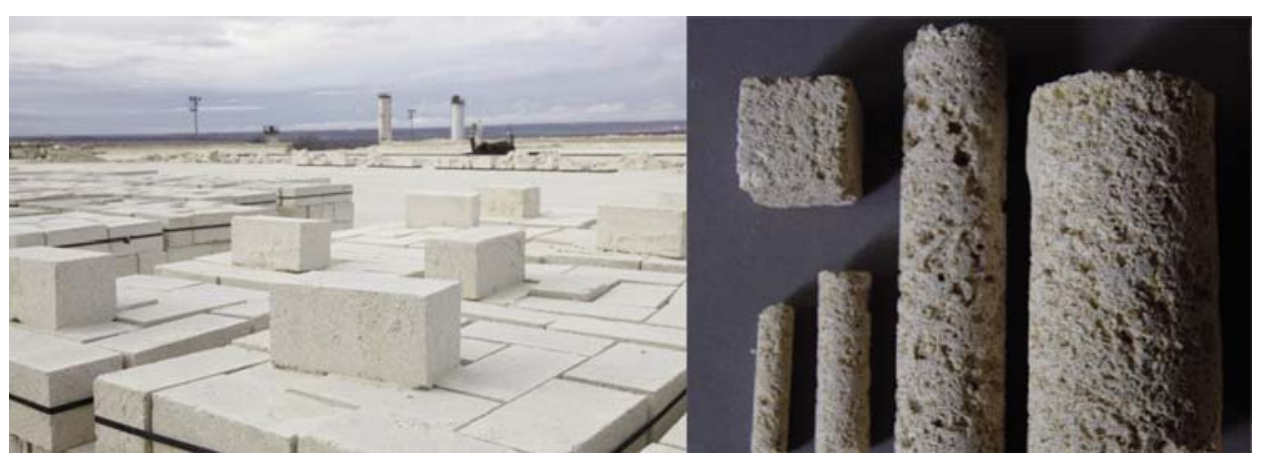

Fig. 2

Sóskút Quarry and Hungarian porous limestone specimens

Table 1

List of tested materials

\begin{tabular}{c|c|c|c}
\hline № & Description of the materials & № & Description of the materials \\
\hline 1. & coarse porous limestone & 8. & repair mortar+50\% limestone agg. (R.r.m. 50\%) \\
2. & fine porous limestone & 9. & repair mortar (M.r.m.) \\
3. & repair mortar (T.r.m.) & 10. & repair mortar+30\% limestone agg. (M.r.m. 30\%) \\
4. & repair mortar+30\% limestone agg. (T.r.m. 30\%) & 11. & repair mortar+50\% limestone agg. (M.r.m. 50\%) \\
5. & repair mortar+50\% limestone agg. (T.r.m. 50\%) & 12. & repair mortar (B.r.m.) \\
6. & repair mortar (R.r.m.) & 13. & repair mortar (K.r.m.) \\
7. & repair mortar+30\% limestone agg. (R.r.m. 30\%) & 14. & repair mortar+30\% limestone agg. (K.r.m. 30\%) \\
\hline
\end{tabular}

\section{Analytical methodology}

Water saturation method (WSM)

The real density, the apparent density and open porosity of the test specimens were determined according to the EN 1936:2007 and EN 1015-10 standards. After measuring the dry weight and the vacuum saturated weight (with distilled water) under hydrostatic pressure of the samples, the apparent porosity was calculated with the Poschlod equation (Poschlod 1990). Under vacuum the fluids can penetrate the pores with a diameter larger than $10 \mu \mathrm{m}$ (Cuevas 1997). Open porosity in mortars was tested 90 days after preparation. The $10 \mathrm{~mm}$-diameter cylindrical oven-dried $\left(50^{\circ} \mathrm{C}\right)$ specimens were used for other measurements.

Mercury intrusion porosimetry (MIP)

The pore size distribution of radii of $0.001 \mu \mathrm{m}$ to $100 \mu \mathrm{m}$ was evaluated by using the mercury intrusion porosimetry technique with a Carlo Erba 2000 (GFZ Potsdam) pore-size mercury porosimeter (Brakel et al. 1981), using the Pascal software (version 1.03). The method is based on the Washburn equation (Washburn 1921). It is ideal for estimating fine pores and coarse pores as well, while the water vapor adsorption method (WVM) may cause errors, especially for coarse-sized pores (Kate and Gokhale 2006). Specimens of $10 \mathrm{~mm}$ in diameter 
were prepared with the length of the samples depending on the apparent density and open porosity, which were determined prior to MIP tests. Samples were oven-dried at a temperature of $70{ }^{\circ} \mathrm{C}$ for at least 24 hours and cooled down in a desiccator. It is important to note that this technique has limitations: it measures the largest entrance of pores, but is not sensitive to the actual inner size of the pore, and is not able to analyze the closed pores (Giesche 2006).

\section{Capillary water absorption}

The capillary water absorption test of hanging cubic samples was undertaken according to the EN 1936:2007 standard. The balance sheet and the samples were placed in a closed plastic cube under standard humidity and temperature. The computer system detected the weight increase ( $0.1 \mathrm{~g}$ accuracy) every 5 seconds, from the beginning of immersion until full saturation. The water absorption coefficient was calculated based on weight increase. The aim was to achieve a complete saturation of the specimens. For each repair mortar and natural stone type, at least 2 specimens were tested.

\section{Compressive strength}

Uniaxial compressive strength was also measured. Tests were performed according to the methodology described in the EN 1015-11:2000 standard, by using a DigiMess M-10 with a maximum load capacity of $200 \mathrm{kN}$ and loading velocity of $0.2 \mathrm{kN} / \mathrm{s}$. Strength tests were performed after consolidating periods of 90 days. The change of the compressive strength during the consolidation period was reported earlier (Szemerey and Török 2011).

\section{Results}

\section{Density and porosity determination with WSM}

These tests focused on the different $\mathrm{B} / \mathrm{Ag}$ content, repair mortar behavior and structure under average conditions (room temperature $-20 \pm 2{ }^{\circ} \mathrm{C}-$ and normal humidity 50-55 RH). The test results (Table 2) show that for most of the repair mortars density and porosity values are relatively close to that of the limestones (samples 1 and 2). Sample sets 9 and 10 have the highest density $\left(2.27 / 2.50 \mathrm{~g} / \mathrm{cm}^{3}\right)$ and the lowest porosity of all $(22.52 / 22.26 \%)$.

Table 2

Mean open porosity; apparent and real density and average pore size of samples

\begin{tabular}{|l|c|c|c|c|c|c|c|c|c|c|c|c|c|c|}
\hline \multicolumn{1}{|c|}{ Sample № } & 1 & 2 & 3 & 4 & 5 & 6 & 7 & 8 & 9 & 10 & 11 & 12 & 13 & 14 \\
\hline $\begin{array}{l}\text { Average open } \\
\text { porosity (\%) }\end{array}$ & 32.2 & 33.78 & 25.55 & 28.2 & 32.47 & 29.85 & 31.78 & 32.83 & 24.6 & 22.5 & 22.3 & 38.6 & 32.72 & 34.59 \\
\hline $\begin{array}{l}\text { Average apparent } \\
\text { density }\left(\mathrm{g} / \mathrm{cm}^{3}\right)\end{array}$ & 1.83 & 1.79 & 1.93 & 1.89 & 1.81 & 1.8 & 1.73 & 1.72 & 2.28 & 2.27 & 2.21 & 1.64 & 1.79 & 1.77 \\
\hline $\begin{array}{l}\text { Average real density } \\
(\%)\left(\mathrm{g} / \mathrm{cm}^{3}\right)\end{array}$ & 2.15 & 2.13 & 2.19 & 2.17 & 2.12 & 2.10 & 2.05 & 2.07 & 2.51 & 2.50 & 2.43 & 2.03 & 2.13 & 2.08 \\
\hline $\begin{array}{l}\text { Average pore size } \\
(\mu \mathrm{m})\end{array}$ & 16.4 & 14.05 & 0.16 & 0.26 & 0.33 & 0.54 & 1.06 & 2.02 & 0.15 & 0.49 & 1.23 & 0.64 & 0.43 & 0.59 \\
\hline
\end{tabular}




\section{Pore size distribution}

The limestones exhibit pore radii ranging from $0.001-100 \mu \mathrm{m}$ and the largest parts of the pores fall into macro-pore categories $(10-100 \mu \mathrm{m})$. Comparing the results of repair mortar with the limestones it is clear that for repair mortars the micro- and meso-pores dominate over macro-pores. Figure 3 shows the result of the pore size distribution. There is a linear correlation between the porosity and density for all samples (Table 2). A greater amount of aggregates increases the percentage of medium and large pore radii $(0.1-100 \mu \mathrm{m})$ in mortars. Nevertheless, fine and coarse limestone show higher pore radii $(<10-100 \mu \mathrm{m})$. From the pore size distributions the average pore size was calculated and is given in Table 2 . The visual comparison of the samples can be found in Figs 3 and 4 .

An increased meso-pore range was measured for all of the repair mortars. The absence of macro-pores is also a typical feature. Repair mortars have their maxima of pore radii larger than $1 \mu \mathrm{m}$ but smaller than $10 \mu \mathrm{m}$, while limestones have their maxima at pore ranges larger than $10 \mu \mathrm{m}$. This result shows that most of the pores are larger than $10 \mu \mathrm{m}$ in the limestone samples (sample 2) while with the repair mortars this pore range is almost undetected (Figs 3 and 4). The majority of the pores of the repair mortars have radii between 1 and $10 \mu \mathrm{m}$. Adding any type of aggregate mixture to repair mortar cause a shift toward larger pores.

1.

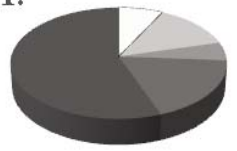

2.

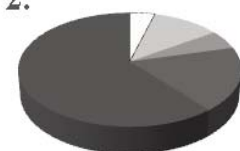

3.

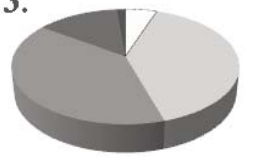

4.

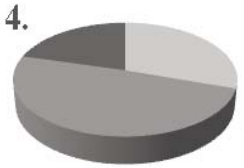

5.

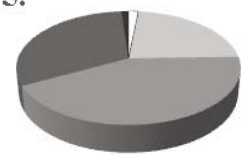

6.

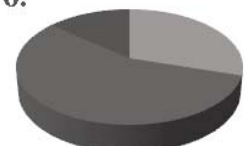

7.

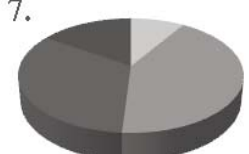

8.

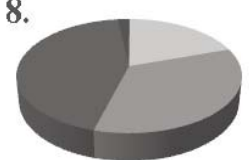

9.

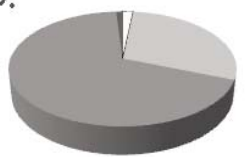

10.

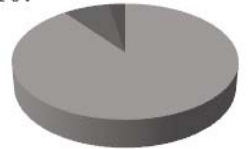

11.

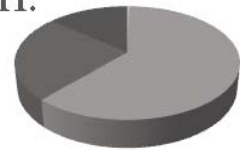

12.

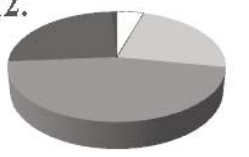

13.

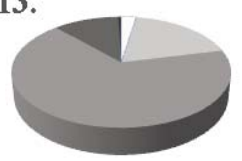

14.

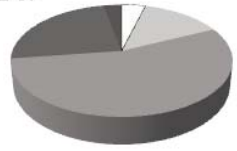

$\square 0.001-0.01 \mu \mathrm{m}$

$0.01-0.1 \mu \mathrm{m}$

01.-1 $\mu \mathrm{m}$

$1-10 \mu \mathrm{m}$

$10-100 \mu \mathrm{m}$

Fig. 3

Visual comparison of the pore size distribution of 14 samples 

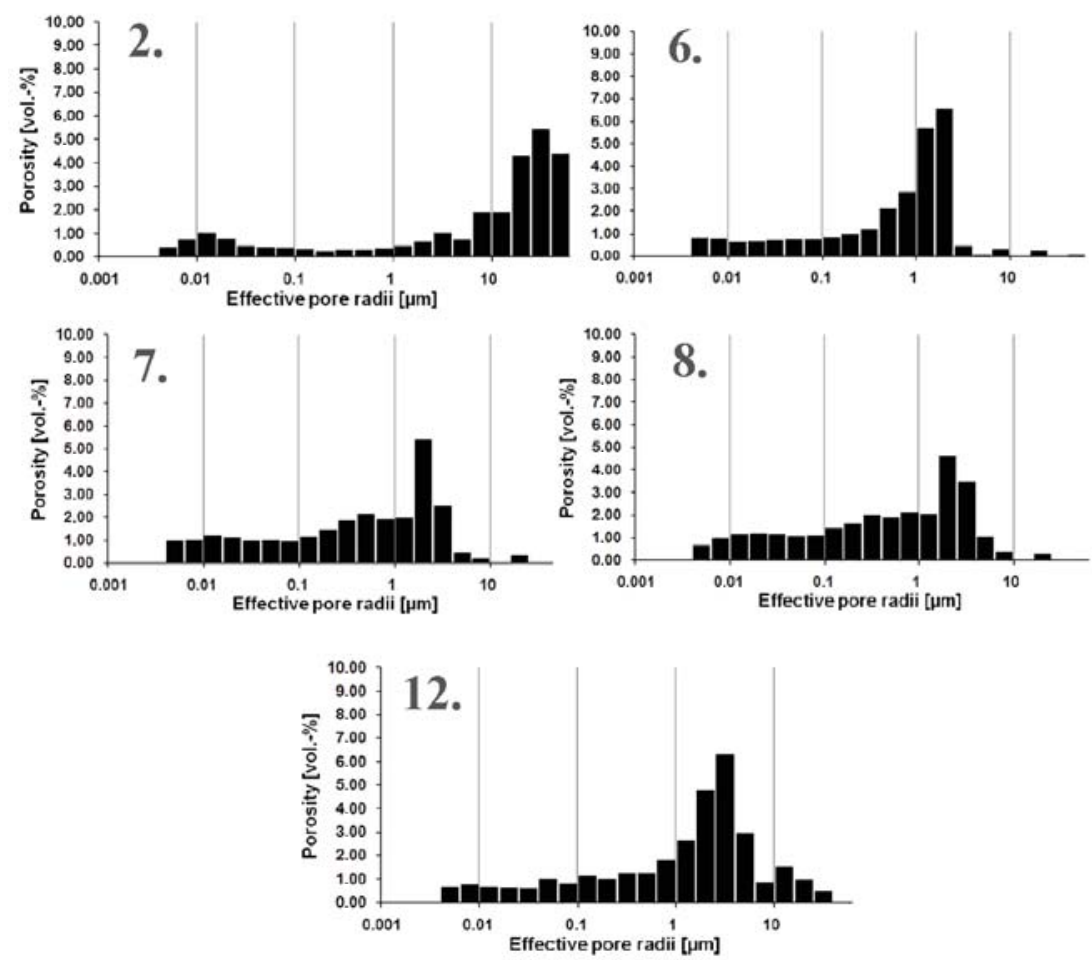

Fig. 4

Comparison of pore size distribution of sample 2 (limestone), and repair mortar samples 6, 7, 8, and 12 (sample explanation is given in Table 1)

\section{Capillary water absorption}

The results of capillary water absorption tests have shown that the capillary water absorption of natural stones is higher than any of the repair mortars. The water absorption coefficients of the different types of repair mortars are very similar to each other, but much lower than that of natural stone. As expected, added lime sand aggregates increased the water absorption coefficient (Table 3). Only the K.r.m. and K.r.m. $+30 \%$ aggregate (sample sets 13 and 14) showed greater

Table 3

Capillary water absorption coefficient (A-coefficient in $\mathrm{kg} / \mathrm{m}^{2 *} \mathrm{~h}^{1 / 2}$ ) of studied samples

\begin{tabular}{|l|c|c|c|c|c|c|c|c|c|c|c|c|c|c|}
\hline Sample № & 1 & 2 & 3 & 4 & 5 & 6 & 7 & 8 & 9 & 10 & 11 & 12 & 13 & 14 \\
\hline $\begin{array}{l}\text { Water } \\
\text { absorption } \\
\text { coefficient }\end{array}$ & 52.3 & 68.55 & 1.98 & 2.16 & 5.71 & 2.05 & 3.32 & 5.11 & 1.62 & 1.77 & 4.54 & 11.83 & 15.95 & 17.25 \\
\hline
\end{tabular}


absorption values compared to other mortars. Adding further amounts of aggregates to this mortar does not increase capillary water absorption to a rate that is comparable to that of limestones.

The comparison of capillary water uptake curves in Fig. 5 clearly demonstrates that the pore volume distribution of sample 2 differs from samples $6,7,8$, and 12 . The A-coefficient of natural stones of 52.26 and $68.55 \mathrm{~kg} / \mathrm{m}^{2} \mathrm{~h}^{1 / 2}$ is unusual and more than 3-4 times larger than any of the pure or modified mortar. The highly active capillary system and extraordinary water uptake of limestone is attributed to a well-connected pore system.

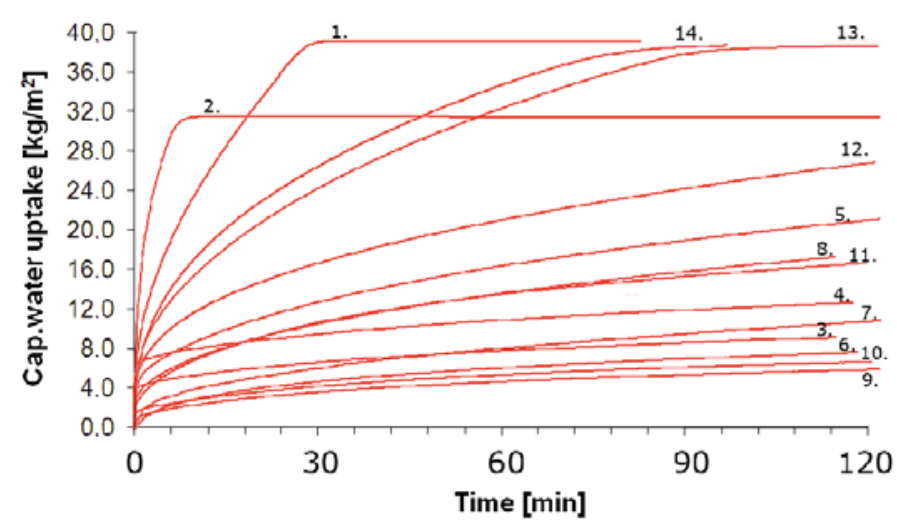

Fig. 5

Comparative water uptake curves all of the samples

\section{Mechanical properties}

The increasing aggregate content of the studied repair mortar causes a more significant decrease in measured compressive strength values (Szemerey and Török 2011). The studied compressive strength values are shown in Fig. 6 in comparison to the open porosity. According to the results, R.r.m $+30 \%$, K.r.m. and T.r.m. $+50 \%$ are close to the natural porous limestone porosity and strength as well. In the case of M.r.m. the added aggregate significantly decreased the strength of the repair mortar. Thirty percent aggregate also decreased the strength of the K.r.m. mortar and 50\% aggregate probably also cause a serious

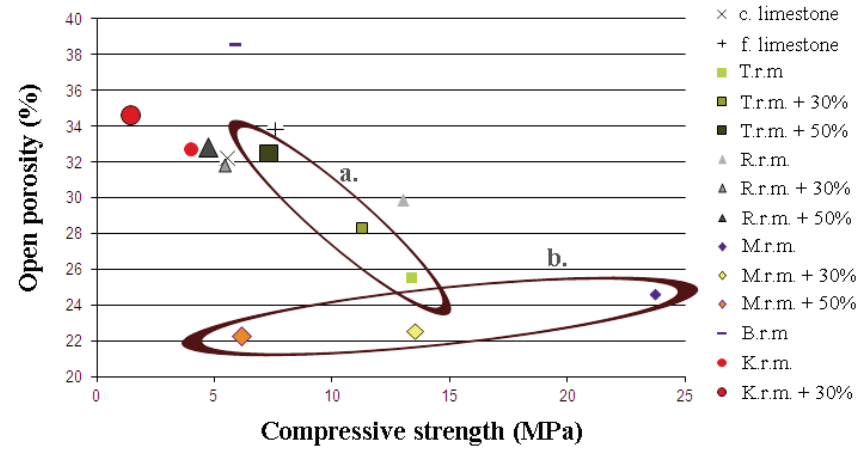

Central European Geology 55, 2012
Fig. 6

Open porosity of the samples compared to the compressive strength (after 90 days). (Sample explanation is given in Table 1) 
decrease. The compressive strength of B.r.m. is almost the same as the case of coarse limestone, but the very high porosity leads to rapid weathering of the mortar (Szemerey and Török 2011). Adding further amount of aggregates to this mortar increases the porosity, except with the M.r.m. set of samples (group "b" in Fig. 6). However, when $30 \%$ and $50 \%$ of aggregate were added, a decrease in compressive strength was observed in every set of sample.

\section{Discussions and conclusion}

As it has been reported (Lanas et al. 2006; Pavia and Toomey 2008) there is a close relation between the pore structure, the mechanical properties and the water absorption of mortars. By adding aggregate these properties can be modified. Our tests have shown that not only the aggregate properties but also the type of the binder, binder/ water ratio, the binder/aggregate ratio, curing conditions and the hardening environment (time, temperature, relative humidity, etc.) of the mortar influences the above-listed parameters. Warm and cold environments can also change the pore structures during slow or rapid hydration (Klisinska-Kopacz et al. 2010). The present paper concludes that aggregate quantity could also have an effect on the mechanical strength and bulk density of the ready-to-use repair mortars. Analyzed dry mortars were compared, both in terms of compressive strength (UCS) vs. porosity, density and water absorption. A close relationship between the pore structures and mechanical properties were found (Fig. 6). Indeed, for most tested materials there is a close correlation between open porosity and compressive strength, with a few exceptions. The transport and accumulation of water in natural stones and repair mortars is a complex process which depends on several features, especially on the type of natural stone, aggregate ratio, structure - but mainly on porosity. Based on the test results, samples are divided into 3 main groups. Group 1 contains samples characterized by high porosity and water absorption coefficient. Limestones with average compressive strength (samples 1 and 2) belong to this group. Group 2 contains samples with medium porosity and low water absorption coefficient (such as sample sets 6, 7, 8, 12, and 13). The final group (group 3) is characterized by repair mortars with low porosity and very low water absorption coefficient (samples 3, 4, 5, 9, 10, 11, 14, and 15). The differences in water absorption and water transport properties of porous limestone and repair mortars are attributed to differences in pore-size distribution. In limestones higher amount of coarse pores, meso- and macro-pores were found, while all the tested repair mortar mixtures have pores in the lower size-range (micro- and meso-pores).

Further studies are essential to the understanding of the practical behavior of repair mortars and compatibility with limestones. Vapor permeability tests can help to clarify the problem. 


\section{Acknowledgements}

This work is connected to the scientific program of the "Development of quality-oriented and harmonized R+D+I strategy and functional model at BME" project. This project is supported by the New Széchenyi Plan (Project ID: TÁMOP-4.2.1/B-09/1/KMR-2010-0002). Some of the tests were performed within the framework of the DAAD MÖB research program (project no. P-MÖB/842). The authors are grateful to S. Heidrun and M. Morales for the technical help in laboratory analyses.

\section{References}

Arns, C.H. 2004: A comparison of pore size distributions derived by NMR and X-ray-CT techniques. - Physica A., 339, pp. 159-165.

Barsottelli, M., G.F. Cellai, F. Fratini, F. Manganelli 2001: The hygrometric behaviour of some artificial stonematerials used as elements of masonry walls. - Materials and Structures, 34, pp. 211-216.

Benachour, Y., C.A. Davy, F. Skoczylas, H. Houari 2008: Effect of a high calcite filler addition upon microstructural, mechanical, shrinkage and transport properties of a mortar. - Cement and Concrete Research, 38, pp. 727-736.

Beck, K., M. Al-Mukhtar 2008: Formulation and characterization of an appropriate lime based mortar for use with a porous limestone. - Environmental Geology, 56, pp. 715-727.

Binda, L, G. Baronio, C. Tedeschi, C. Tiraboschi 2003: Characterisation of the materials used in the construction of the Noto Cathedral. - Construction and Building Materials, 17, pp. 557-571.

Brakel, J.V., S. Modry, M. Svata 1981: Mercury porosimetry: State of the art. - Powder technology, 29, pp. 1-12.

Budak, M., P. Maravelaki-Kalaitzaki, N. Kallithrakas-Kontos 2008: Chemical characterization of Crean clays for the design of restoration mortars. - Microchim. Acta, 162, pp. 325-331.

Bultrinim, G., I. Fragala, G.M. Ingo, G. Lanza 2006: Minero-petrographic, thermal and microchemical investigation of historical mortars used in Catania (Sicily) during the XVII century A.D. Applied Physics, 83, pp. 529-536.

Cuevas, C.D.L. 1997: Pore structure characterization in rock salt. - Engineering Geology, 47, pp. 17-30.

Demarco, M.M., E. Jahns, J. Rüdrich, P. Oyhantcabal, S. Siegesmund 2007: The impact of partial water saturation on rock strength: an experimental study on sandstone. - Z. dt. Ges. Geowiss, 158/4, pp. 869-882.

Franzen, C., P.W. Mirwald 2004: Moisture content of natural stone: static and dynamic equilibrium with atmospheric humidity. - Environmental Geology, 46, pp. 391-401.

Giesche, H. 2006: Mercury porosimetry: A general (practical) overview. Part 1. - Part. Syst. Charact, 23, pp. 1-11.

Hanley, R., S. Pavia S. 2008: A study of the workability of natural hydraulic lime mortars and its influence on strength. - Materials and Structures, 41, pp. 373-381.

Hassan, K.E., J.J. Brooks, L. Al-alawi 2001: Compatibility of repair mortars with concrete in hot-dry environment. - Cement and Concrete Composites, 23, pp. 93-101.

Karaca, Z. 2010: Water absorption and dehydration of natural stones versus time. - Construction and Building Materials, 24, pp. 786-790.

Katem, J.M., C.S. Gokhale 2006: A simple method to estimate complete pore size distribution of rocks. - Engineering Geology, 84, pp. 48-69.

Klisinska-Kopacz, A., R. Tišlova, G. Adamski, R. Kozlowski 2010: Pore structure of historic and repair Roman cement mortars to establish their compatibility. - Journal of Cultural Heritage, 11, pp. 404-410. 
Lanas, J., J.I. Alvarez 2003: Masonry repair lime-based mortars: Factors affecting the mechanical behavior. - Cement and Concrete Research, 33, pp. 1867-1876.

Lanas, J., R. Sirera, J.I. Alvarez 2005: Study of the mechanical behaviour of cmasonry lime-based mortars cured and exposed under different conditions. - Cement and Concrete Research, 36, pp. 961-970.

Lanas, J., P.J.L. Bernal, M.A. Bello, J.I. Alvarez, 2006: Mechanical properties of masonry repair dolomitic lime-based mortars. - Cement and Concrete Research, 36, pp. 95--960.

Laskar, A.I., R. Kumar, B. Bhattacharjee 1997: Some aspects of evaluation of concrete through mercury intrusion porosimetry. - Cement and Concrete Research, 27, pp. 93-105.

Maravelaki-Kalaitzaki, P. 2005: Black crusts and patinas on Pentelic marble from the Parthenon and Erechtheum (Acropolis, Athens): characterization and origin. - Analytica Chimica Acta, 32, pp. 187-198.

Marques, S.F., R.A. Ribeiro, L.M. Silva, V.M. Ferreira, J.A. Labrincha 2006: Study of rehabilitation mortars: Construction of a knowledge correlation matrix. - Cement and Concrete Research, 36, pp. 1894-1902.

Middendorf, B., J.J. Hughes, K. Callebaut, G. Baronio, I. Papayianni 2005a: Investigative methods for the characterisation of historic mortars part 1: Minerological characterization. - Materials and Structures, 38, pp. 761-769.

Middendorf, B., J.J. Hughes, K. Callebaut, G. Baronio, I. Papayianni 2005b: Investigative methods for the characterisation of historic mortars part 2: Chemical characterization. - Materials and Structures, 38, pp. 771-780.

Papayianni, I. 2006: The longevity of old mortars. - Applied Physics A., 83, pp. 685-688.

Pavia, S., B. Fitzgerald, E. Treacy 2006: An assessment of lime mortars for masonry repair. - Concrete Research in Ireland Colloquium, University College Dublin, pp. 101-108.

Pavia, S., B. Toomey 2008: Influence of the aggregate quality on the physical properties of natural feebly-hydraulic lime mortars. - Materials and Structures, 41, pp. 559-569.

Pavia, S., S. Caro S. 2008: An investigation of Roman mortar technology through the petrographic analysis of archaeological material. - Construction and Building Materials, 22, pp. 1807-1811.

Pecchioni, E., P. Malesani, B. Bellucci, F. Fratini 2005: Artificial stones utilised in Florence historical palaces between the XIX and XX centuries. - Journal of Cultural Heritage, 6, pp. 227-233.

Posclod, K. 1990: Das Wasser im Porenraum klistaliner Naturwerksteine und sein Einfluss auf die Verwitterung. - Münchener Geowissenschaftliche Abhandlungen, Reihe B, Allgemmeine und Angewandte Geologie, 7 Pfeil, München.

Prikryl R., A. Štastná 2010: Contribution of clayey-calcareous silicite to the mechanical properties of structural mortared rubble masonry of the medieval Charles Bridge in Prague (Czech Republic). - Engineering Geology, 115, pp. 257-267.

Prikryl R., Z. Weishauptová, M. Novotná, J. Prikrylová, A. Štastná 2010: Physical and mechanical properties of the repaired sandstone ashlars in the facing masonry of the Charles Bridge in Prague (Czech Republic) and an analytical study for the causes of its rapid decay. Environmental Earth Sciences, 63, pp. 1623-1639.

Rodrigues, J.D., A. Grossi 2007: Indicators and ratings for the compatibility assessment of conservation actions. - Journal of Cultural Heritage, 8, pp. 32-43.

Roles, S., K. Vandersteen, J. Carmeliet 2003: Measuring and simulating moisture uptake in a fractured porous medium. - Advances in Water Resources, 26, pp. 237-246.

Siegesmund, S., Á. Török, A. Hüpers, C. Müller, W. Klemm 2007: Mineralogical, geochemical and microfabric evidences of gypsum crusts: a case study from Budapest. - Environmental Geology, 52, pp. 358-397.

Sinan, C. 2003: Aggregate/mortar interface: influence of silica fume at the micro- and macro-level. Cement and Concrete Composites, 25, pp. 557-564.

Szemerey, K.B., Á. Török 2008: Múemléki plasztikus kőkiegészítô anyagok jellemzői és felhasználhatósága. - In: Török, Á., B. Vásárhelyi (Eds): Mérnökgeológia-Kőzetmechanika, Budapest, pp. 203-214. 
134 B. Szemerey-Kiss, Á. Török

Szemerey, K.B., Á. Török 2010: Kőkiegészítók kompatibilitási vizsgálata. - KO, XII/3, pp. 27-30.

Szemerey, K.B., Á. Török 2011: Time-dependent changes in the strength of repair mortar used in loss compensation of stone. - Environmental Earth Science, 63, pp. 1613-1621.

Szemerey, K.B., Á. Török 2011: Salt durability tests of repair mortars used in the restoration of porous limestones. - In: Ioannou, I., M. Theodoridou (Eds): Salt Weathering on Buildings and Stone Sculptures, SWBSS, Limassol, pp. 323-330.

Swe, Y., T.O. Chiaki 2010: Role of pore size distribution in salt uptake, damage, and predicting salt susceptibility of eight types of Japanese building stones. - Engineering Geology, 115, pp. 226-236.

Tsakiroglou, C.D., A.C. Payatakes 2000: Characterization of the pore structure of reservoir rocks with the aid of serial sectioning analysis, mercury porosimetry and network simulation. - Advances in Water Resources, 23, pp. 773-789.

Tunçoku, S.S., E.N. Caner-Saltik 2006: Opal-A rich additives used in ancient lime mortars. - Cement and Concrete Research, 36, pp. 1886-1893.

Washburn, E.W. 1921: The dynamics of capillary flow. - Physical Review, 17, pp. 273-283. 